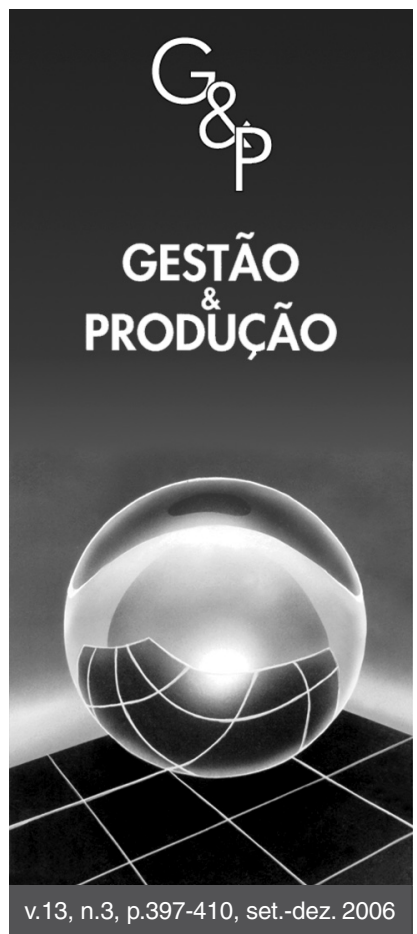

\title{
LOGÍSTICA REVERSA NUMA EMPRESA DE LAMINAÇÃO DE VIDROS: UM ESTUDO DE CASO
}

\author{
Marcus Eduardo Gonçalves \\ Fernando Augusto Silva Marins \\ Grupo de Otimização e Logística - GOL, \\ Departamento de Engenharia de Produção, Campus de Guaratinguetá, \\ Universidade Estadual Paulista - UNESP, SP, Brasil, \\ e-mail: pro99029@ hotmail.com, fmarins@ feg.unesp.br
}

Resumo

Este trabalho apresenta uma aplicação da Logística Reversa numa empresa multinacional que atua na área de laminação de vidros no Brasil. Na empresa estudada, a sucata gerada pelos seus clientes pode ser usada para realimentar o seu processo de produção. Inicialmente, são discutidos os principais aspectos relacionados ao tema, tais como, definição de Logística Reversa, ciclo de vida do produto, motivos e destinos do retorno, além dos fatores que influenciam a eficiência de um processo de Logística Reversa. A seguir, ilustradas pelo estudo de caso, são apresentadas e comentadas as etapas para uma implementação de um sistema de Logística Reversa ser bem sucedida. Finalmente, comentam-se as dificuldades, ganhos e vantagens competitivas obtidas por empresas que adotaram soluções da Logística Reversa, em particular na empresa em que o estudo de caso foi desenvolvido.

Palavras-chave: gerenciamento da cadeia de suprimentos, logística reversa, estudo de caso, laminação de vidros.

\section{Introdução}

Logística e Gerenciamento da Cadeia de Suprimentos (Supply Chain Management) são conceitos importantes que representam um paradoxo interessante, pois dizem respeito a uma das mais antigas e, por outro lado, recémdescoberta atividade de negócios (Bowersox e Closs, 2001). É muito difícil visualizar algum produto que chegue ao cliente sem suporte logístico, porém, somente há relativamente pouco tempo, as empresas têm se concentrado na Logística e Gerenciamento da Cadeia de Suprimentos como fontes de vantagens competitivas.

De fato, é bem aceito no setor empresarial que nenhuma companhia pode ser melhor que seu sistema logístico. Isto vem se tornando cada vez mais importante, dada a crescente redução do ciclo de vida dos produtos, da diversidade destes e da concorrência global cada vez mais intensa. Desse modo, Logística e Gerenciamento da Cadeia de Suprimentos hoje representam um grande de- safio e uma grande oportunidade para muitas empresas (Chopra e Meindl, 2003).

Nos últimos anos, a Logística vem apresentando uma evolução constante, sendo hoje um dos elementos-chave na estratégia competitiva das empresas. No início, era confundida com o transporte e a armazenagem de produtos. Hoje, é o ponto nevrálgico da cadeia produtiva integrada, atuando em estreita consonância com o moderno Gerenciamento da Cadeia de Suprimentos (Novaes, 2001). De fato, o interesse no efetivo e eficaz Gerenciamento da Cadeia de Suprimentos vem crescendo desde os anos 80, quando as empresas perceberam os benefícios de relacionamentos colaborativos dentro e além dos limites da sua própria organização.

Há várias definições para o Gerenciamento da Cadeia de Suprimentos. Aqui, apresenta-se uma definição, proposta pelo SCC - Supply Chain Council (www.supplychain.org, acesso em 20/08/2004): 
O Gerenciamento da Cadeia de Suprimentos engloba todos os esforços envolvidos na produção e entrega de um produto final, desde o fornecedor do fornecedor (2nd Tyer) até o cliente do cliente. Quatro processos básicos planejar (plan), buscar recursos (source), fazer (make), entregar (delivery) - envolvem estes esforços, que incluem gerenciar suprimentos e demanda, obter matéria-prima e componentes, manufaturar e montar, armazenar e rastrear os estoques, gerenciar os pedidos, distribuição por todos os canais e entregar ao cliente.

Assim, o Gerenciamento da Cadeia de Suprimentos coordena e integra todos os processos industriais e comerciais dos vários componentes de uma dada Cadeia; interligando todos os parceiros, incluindo departamentos internos de cada organização envolvida e os parceiros externos, como fornecedores, transportadores, operadores logísticos e fornecedores de sistemas de informação. Os gerentes das empresas de uma Cadeia de Suprimentos têm interesse no sucesso das outras empresas parceiras, de modo que a cadeia, como um todo, seja competitiva. (Lummus e Vokurka, 1999)

Pode-se conceituar Logística adotando a definição do CSCMP - Council of Supply Chain Management Professionals (www.cscmp.org, acesso em 10/10/2004):

Logística é a parte do Gerenciamento da Cadeia de Suprimentos que inclui os processos de planejar, implementar e controlar de maneira eficiente e eficaz o fluxo e a armazenagem de produtos, bem como os serviços e informações associados, cobrindo desde o ponto de origem até o ponto de consumo, com o objetivo de atender aos requisitos do consumidor.

Mais recentemente, um novo aspecto veio se somar aos diversos processos que já eram considerados importantes para o adequado Gerenciamento da Cadeia de Suprimentos, que foi o de se considerar o gerenciamento dos retornos oriundos de produtos e de embalagens. Surgiu, assim, uma nova dimensão da Logística e do Gerenciamento da Cadeia de Suprimentos, que foi o conceito de Logística Reversa - LR.

Muitas organizações, profissionais e pesquisadores em Logística têm procurado definir LR. Como esse termo pode ser considerado novo, aqui ele será associado a todas as atividades relacionadas ao produto/serviço após a venda, sendo que o seu objetivo principal é otimizar ou tornar mais eficientes as atividades do pós-venda, resultando, portanto, em economia de recursos financeiros.

De fato, LR está se tornando parte relevante do Gerenciamento da Cadeia de Suprimentos; muitas empresas que, até há pouco tempo, não lhe davam a devida importância, estão revendo essa postura (Giuntini e Andel, 1995).
Aqui será apresentado um estudo de caso desenvolvido numa empresa de laminação de vidros, mostrando as vantagens competitivas obtidas, bem como as dificuldades enfrentadas, numa empresa em que seu processo de produção pode ser realimentado pela sucata gerada pelos seus clientes. Mostra-se que uma implementação eficiente de sistemas de LR pode levar à redução de custos na Cadeia de Suprimentos.

Segundo Stock (1998), a Logística Reversa pode ser analisada de dois pontos de vista:

- Da perspectiva da logística como negócio, se refere ao papel da Logística no retorno de produtos, na redução de uso de matéria-prima virgem, no uso da reciclagem, na substituição de materiais, no reuso de materiais, na disposição de resíduos, no recondicionamento, no reparo e no remanufaturamento de produtos; e

- Da perspectiva da logística como engenharia, se refere ao gerenciamento dos processos acima e é como um modelo sistemático de negócios que aplica as melhores metodologias de engenharia e administração conhecidas para fechar, com lucratividade, o ciclo em uma Cadeia de Suprimentos.

Aqui se tem a preocupação com o problema associado a como diminuir o impacto da disposição de vidros em aterros sanitários, fazendo isso de forma rentável para todos os parceiros numa cadeia de suprimentos de laminação de vidros. O trabalho foi realizado considerando-se ambos os pontos de vista abordados anteriormente.

A preocupação com o fluxo reverso já é comum a várias empresas, como as dos fabricantes de bebidas, que têm de gerenciar o retorno de embalagens dos pontos de vendas para os pontos de distribuição, dos fabricantes de pneus, dos fabricantes de baterias de celulares e as siderúrgicas - em que parte dos insumos de produção provém da sucata gerada pelos clientes (Rogers e Tibben-Lembke, 1999).

Nos últimos anos, a legislação ambiental têm encorajado várias empresas a decidir pela implementação de políticas de LR para seus produtos e embalagens, por causa da necessidade de diferenciação entre serviços oferecidos (devido à crescente competição no mercado) e as políticas de continuamente cortar custos (Moritz et al., 2001 e Fleischmann et al., 2001).

A título de ilustração, a Comissão Européia (European Commission) estabeleceu um conjunto de regras para se fazer o gerenciamento adequado de embalagens (González-Torre et al., 2004). A redução de aterros sanitários, bem como o aumento da reutilização, reciclagem e incineração foram as principais metas da Diretiva de Lixo Resultante de Embalagens (Packaging Waste Directive) 94/62/EC (http://www.pro-e.org/05europe/text/94_ 62_EC.pdf, acesso em 14/02/2005), alterada pela Diretiva 2004/12/EC (http://europa.eu.int/eur-lex/pri/en/ 
oj/dat/2004/1_047/1_04720040218en00260031.pdf, acesso em 14/02/2005). Os países membros da União Européia deveriam ter implementado essa Diretiva até 2001, mas muitos ainda não o fizeram.

Com esses mesmos objetivos, há a Legislação Européia sobre Retornos (European Take-back Legislation) no setor de produtos eletrônicos (Toffel, 2003). Essa legislação faz com que as indústrias desse setor financiem projetos que visem ao gerenciamento, à reciclagem e disposição final de resíduos de produtos eletrônicos. Alguns exemplos resultantes de aplicação dessa legislação estão no sítio http://www.ecocycle.org/zero/takeback.cfm (acesso em 14/02/2005).

Uma interessante revisão bibliográfica sobre LR até 1998 foi feita por Carter e Ellram (1998) que apresentam os fatores que influenciam a LR e como eles se diferenciam daqueles que influenciam a logística tradicional. Além disso, são apresentadas proposições teóricas e um modelo com direcionadores e restrições para programas de LR, bem como direções para pesquisas futuras.

Em Leite (2003), que é o primeiro livro nacional sobre Logística Reversa, há uma excelente introdução ao tema com a apresentação de vários estudos de casos desenvolvidos no Brasil (como por exemplo, o setor de latas de alumínio, de garrafas PET, de óleos lubrificantes, de plásticos, de ferro e aço) e no exterior (como, por exemplo, a Sears \& Roebuck Company e a Bristol-Myers Squibb). Para maiores detalhes, podem ser consultados os sítios (acessos em 19/02/2005):

- http://www.abal.org.br;

- http://www.abipet.org.br;

- http://www.reciclagem.pcc.usp.br;

- http://www.cempre.org.br; e

- http://www.latasa.com.br.

Apesar da relevância atual e futura da Logística Reversa, a literatura disponível sobre o tema ainda pode ser considerada insuficiente, mas está rapidamente crescendo.

O trabalho considerado pioneiro foi aquele publicado por Lund (1984), no qual o autor define o conceito de remanufaturar, discute como fazer de maneira eficiente e lucrativa esse remanufaturamento, quais as economias de energia resultantes, bem como quais os benefícios sociais que poderiam advir disso.

Aqui, procura-se contribuir para essa área da LR, conhecida como sistemas de remanufatura ou sistema de manufatura com realimentação (recoverable manufacturing systems, closed-loop systems), explorando os conceitos e metodologias disponíveis na literatura para o estudo de caso da laminação de vidros.

Esse tipo de sistema de remanufatura busca minimizar os impactos no meio ambiente por meio da reutilização de materiais, reduzindo o uso de energia e também o uso de aterros para rejeitos industriais.
Vários autores, como Guide Jr e Van Wassenhove (2001), Linton et al. (2002), Giuntini e Gaudette (2003), Guide Jr et al. (2003), Fleischmann et al. (2003), Ferrer e Ketzenberg (2004), Van Nunen e Zuidwijk (2004), Flapper e Teunter (2004) e Heese et al. (2005), têm analisado esse tipo de sistema e proposto contribuições importantes para o avanço da LR.

Outro relevante setor de pesquisa em LR tem sido o de desenvolvimento de modelos quantitativos e algoritmos da Pesquisa Operacional. Segundo Fleischmann et al. (1997 apud González-Torre et al., 2004), os modelos desenvolvidos neste campo podem ser divididos em três categorias: para problemas de planejamento da distribuição; para o controle de estoques; e para o planejamento da produção.

Algumas das mais significativas contribuições nessa área podem ser encontradas em Caruso et al. (1993), Kroon e Vrijens (1995), Lai et al. (1995), Del Castillo e Cochran (1996), Van Der Laan et al. (1996), Fleischmann et al. (1997), Krikke et al. (1999), Teunter et al. (2000), Fleischmann (2001a), Minner(2003), Kiesmüllere Scherer, (2003), Dobos (2003) e Teunter e Flapper (2003).

Dentre os vários grupos de pesquisa com interesse em LR, destaca-se o European Working Group on Reverse Logistics (http://www.fbk.eur.nl/OZ/REVLOG, acesso em 21/08/2004), com várias publicações (Dekker et al., 2004). Para exemplificar, podem ser citados artigos relacionados com o projeto de redes logísticas reversas, com tecnologia de informação voltada para a LR, entre outros.

Com essa sucinta revisão bibliográfica, tentou-se mostrar a importância da LR, bem como as oportunidades que podem aparecer devido a sua adoção pelas empresas.

O artigo está estruturado da seguinte forma: na seção 2, estão os objetivos deste trabalho e considerações relativas à metodologia de pesquisa adotada; na seção 3 , tem-se a descrição do processo de Logística Reversa e dos principais conceitos associados; na seção 4, apresenta-se a situação abordada no estudo de caso; na seção 5, descreve-se a transição para o processo de Logística Reversa desenvolvido no estudo de caso; na seção 6 , são descritos os fatores que influenciam a eficiência do processo de Logística Reversa; e na seção 7, estão as considerações finais do trabalho, seguidas de possíveis direções de pesquisa futuras.

\section{Objetivos e metodologia de pesquisa}

\subsection{Objetivos do trabalho}

Como objetivos gerais este estudo se propõe a disseminar a importância da Logística Reversa, fazer um sumário da bibliografia representativa das contribuições científicas publicadas, apresentar sua conceituação e a sistemática recomendada para o seu uso adequado.

Além disso, teve-se como objetivos específicos, apresentar um exemplo de aplicação bem sucedida de um sis- 
tema de Logística Reversa do reaproveitamento das sucatas geradas pelos clientes de uma empresa de laminação de vidros no Brasil, ilustrando assim o uso da sistemática geral da Logística Reversa e das recomendações do modelo de referência em Cadeias de Suprimentos - SCOR (Supply Chain Operations Reference) - de responsabilidade do SCC (Supply Chain Council).

O trabalho foi realizado por uma equipe de profissionais da empresa laminadora de vidros, tendo como coordenador o primeiro autor do artigo e na tarefa de consultor, o segundo autor.

\subsection{Abordagem da pesquisa}

As abordagens de pesquisa caracterizam como será realizado um processo de investigação com respeito a um problema e, também, identificam os métodos e tipos de pesquisa mais adequados para a situação de interesse.

Essas abordagens dependem da natureza do problema, da sua formulação, da teoria existente, do referencial teórico-cultural e do grau de proximidade do pesquisador com o objeto de estudo (Berto e Nakano, 1998). Elas condicionam a maneira pela qual a pesquisa se realizará, como será feita a pesquisa bibliográfica, como se desenvolverá a coleta e a análise dos dados, bem como a discussão dos resultados obtidos (Lakatos e Marconi, 1991 e Cervo e Bervian, 1996, apud Berto e Nakano, 1998).

Tradicionalmente, na área da Engenharia de Produção, adotam-se abordagens de pesquisa denominadas quantitativas, que têm natureza experimental, com hipóteses bem formuladas. Têm como base os métodos lógicodedutivos e buscam explicar relações de causa e efeito, procurando, por meio de generalização dos resultados, permitir replicações.

Nessas abordagens, incluem-se os estudos do tipo "antes e depois", em que são feitas análises estáticas da realidade, usando-se amostras e nas quais inexiste contato entre o pesquisador e o objeto do estudo. Aqui, incluem-se os surveys, estudos teórico-conceituais, diagnósticos, modelagens e simulações que recriam artificialmente a realidade com o uso de dados quantitativos (Berto e Nakano, 1998).

Já as pesquisas qualitativas procuram fazer a interligação entre a teoria existente e o que se observa na prática por meio da descrição e interpretação de fatos isolados, privilegiando o conhecimento das relações entre contexto e ação. Adota-se, aí, o método indutivo. Assim, pelas análises fenomenológicas e pelo julgamento do pesquisador, esse tipo de pesquisa pode possibilitar a comparação entre casos (Berto e Nakano, 1998).

Desse modo, na pesquisa qualitativa, a objetividade é substituída pelo subjetivismo, e a vivência do pesquisador com o objeto de análise permite a observação direta de aspectos relevantes da situação.

Nesse caso, as variáveis são predicados, atributos, propriedades, características e/ou valores mensuráveis encontrados nos objetos de estudo e servem para testar as relações de valor monetário, índices de qualidade e de produtividade, entre outros, que sejam necessários para a verificação das hipóteses formuladas. Os tipos mais comuns são: estudo de caso; observação participante; pesquisa participante; e pesquisa ação (Berto e Nakano, 1998).

Dada a natureza dos objetivos do trabalho, optou-se por realizar uma abordagem de pesquisa do tipo Estudo de Caso; na qual se realiza a análise aprofundada de um ou mais objetos (casos), fazendo uso de múltiplos instrumentos de coleta de dados e intensa interação do pesquisador com o objeto de pesquisa. Portanto, um estudo de caso contempla a utilização conjunta de observação direta da realidade e lógica indutiva.

Na seção 3, apresenta-se a conceituação de Logística Reversa, sua natureza e características.

\section{O processo de logística reversa}

Antes de se conceituar Logística Reversa, deve-se atentar para três aspectos relevantes com respeito a produtos e suas respectivas embalagens:

- Do ponto de vista logístico, o ciclo de vida de um produto não se encerra com a sua entrega ao cliente. Produtos que se tornam obsoletos, danificados ou não funcionam devem retornar ao seu ponto de origem para serem adequadamente descartados, reparados ou reaproveitados;

- Do ponto de vista financeiro, existe o custo relacionado ao gerenciamento do fluxo reverso, que se soma aos custos de compra de matéria-prima, de armazenagem, transporte e estocagem e de produção, já tradicionalmente considerados na Logística; e

- Do ponto de vista ambiental, devem ser considerados e avaliados, os impactos do produto sobre o meio ambiente durante toda sua vida. Este tipo de visão sistêmica é importante para que o planejamento da rede logística envolva todas as etapas do ciclo do produto.

Então, é interessante analisar uma situação do ponto de vista holístico (como uma combinação dos três pontos de vista acima descritos) para permitir o planejamento da rede logística de forma a englobar todas as fases do ciclo de vida dos produtos, os custos associados e os impactos ambientais decorrentes.

Uma ferramenta adequada para esse enfoque é a Análise de Ciclo de Vida (Life Cycle Analysis - LCA) a qual é recomendada pela ISO 14000 (http://www.gdrc.org/ uem/lca/life-cycle.html, acesso em 10/03/2005). A LCA envolve um estudo detalhado desde a obtenção da matéria-prima do produto, na sua produção, distribuição, uso, possível reuso ou reciclagem, ou ainda, na sua disposição final. Ela permite determinar quanto será usado de energia e de matéria-prima, bem como qual a quantidade de 
resíduos sólidos, líquidos e gasosos será gerada em cada estágio do ciclo de vida do produto.

Após estas observações preliminares, pode-se definir Logística Reversa como sendo o processo de planejamento, implementação e controle, do fluxo de matérias-primas, da produção e do produto acabado (e seu fluxo de informação), do ponto de consumo até a origem, com o fim de recapturar valor ou oferecer um destino ecologicamente adequado. Essa é a definição apresentada pelo Reverse Logistics Executive Council - RLEC (www.rlec.org, acesso em 21/08/2004), que é uma organização (com fins não lucrativos), associada ao CSCMP, que se preocupa exclusivamente com o desenvolvimento das melhores práticas na área. Este processo está ilustrado nas Figuras 1 e 2.

A natureza do processo de Logística Reversa depende do tipo de material e o motivo pelo qual ele entrou no sistema. Os produtos, em geral, retornam devido a uma necessidade de reparo, reciclagem, descarte ou simplesmente porque os clientes os devolveram. A Figura 3 exemplifica várias situações possíveis.

Outro aspecto relevante é que o fluxo reverso de produtos pode ser utilizado por uma empresa para manter reduzidos os estoques do cliente, diminuindo os riscos

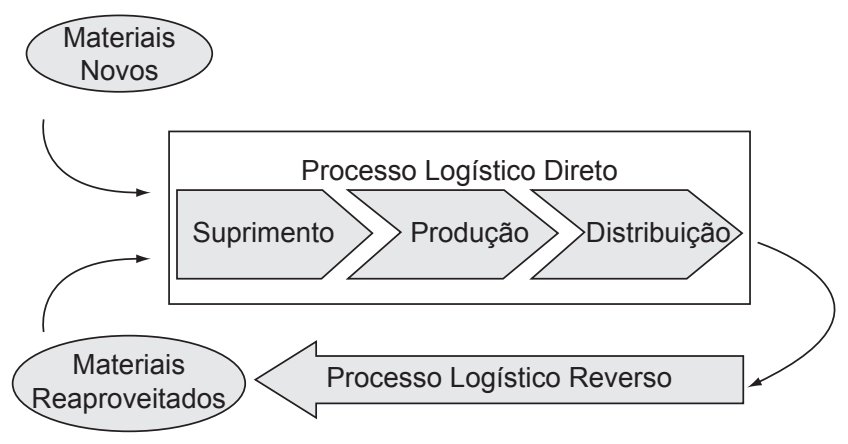

Figura 1. Processo Logístico: Direto e Reverso (Lacerda, 2002 - p. 2). deste com a manutenção dos itens de baixo giro ou que possam ficar obsoletos rapidamente.

Para incentivar a compra de todo o mix de produtos, algumas empresas aceitam a devolução de itens que não tiveram boa aceitação pelo consumidor, como é o caso de fabricantes de CDs de música e livros; nesses casos, embora os custos de devolução possam ser elevados, os custos de perda de vendas seriam bem maiores.

Dentre as muitas indústrias que aplicam técnicas de Logística Reversa na prática, podem ser relacionadas, ainda, as indústrias de ferro e aço, companhias de aviação e de produtos para o setor médico (Dowlatshahi, 2000).

Uma boa referência para estudos de casos em Logística Reversa é o livro de Stock (1998), que fornece informações sobre procedimentos de LR adotados por várias empresas, tais como: Volvo Car Corporation, Orbis Corporation e Ryder Systems, entre muitas outras.

Segundo Rogers e Tibben-Lembke (1999), em uma pesquisa realizada com empresas americanas que adotam o sistema de Logística Reversa, pode-se ter os impactos financeiros apresentados no Quadro1.

No Quadro 1, eventuais reduções observadas nos lucros foram ocasionadas por falhas na implementação da LR ou devido à existência de legislação ambiental proibindo o reuso de produtos e/ou de suas embalagens e, nesse último caso, devia-se fazer a disposição em aterros ou incinerar o material.

Na seqüência, descreve-se o ambiente em que foi desenvolvido o estudo de caso.

\section{Apresentação do problema}

A empresa, em que foi desenvolvido o estudo de caso, localiza-se no Estado de São Paulo e é responsável pela produção do PVB (Polivinilbutiral). O PVB é utilizado como uma película de proteção intercalada nos vidros de automóveis, carros e aviões. Possui, além disto, outras

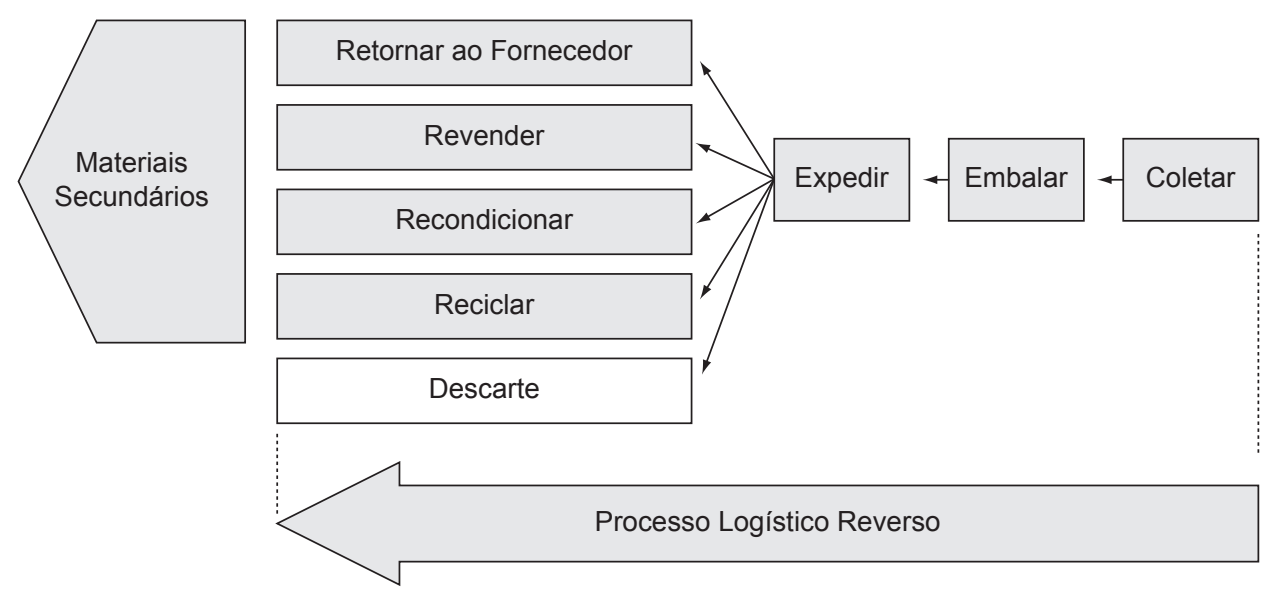

Figura 2. Processo Logístico Reverso (Lacerda, 2002 - p. 3). 


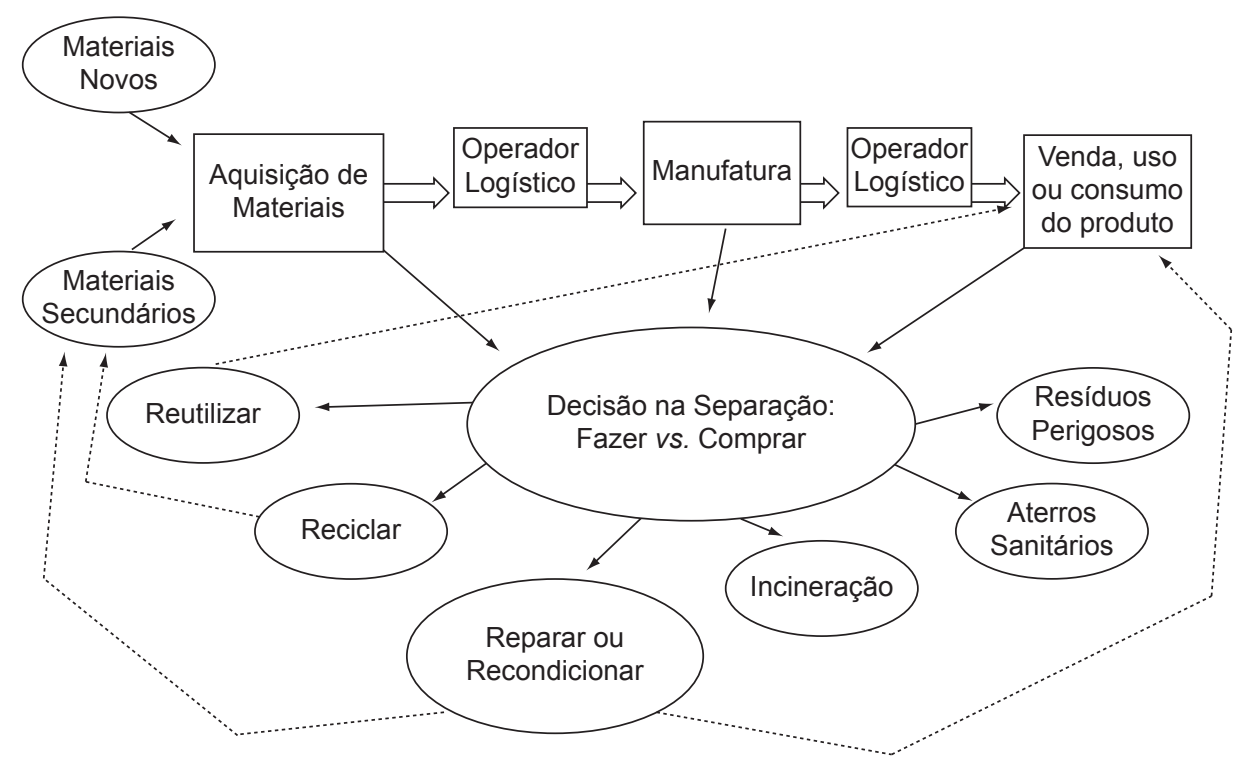

Figura 3. Origens e Destinos de Material Retornado (adaptado de Stock, 1998 - p. 22 ).

Quadro 1. Impactos da Logística Reversa (adaptado do Apêndice B - p. 223 de Rogers e Tibben, 1999).

\begin{tabular}{lcc}
\hline \multicolumn{1}{c}{ Fator } & Média $(\mu)$ & Desvio Padrão $(\sigma)$ \\
\hline $\begin{array}{l}\text { Impacto da LR nos lucros } \\
\text { Porcentagem dos custos } \\
\text { da LR no custo logístico }\end{array}$ & $3,7 \%$ & $5,9 \%$ \\
total & $3,9 \%$ & $6,3 \%$ \\
$\begin{array}{l}\text { Redução do Lucro total } \\
\text { (alguns casos) }\end{array}$ & $4,2 \%$ & $9,8 \%$ \\
\hline
\end{tabular}

funcionalidades como proteção acústica, reflexão de imagens, filtro UV e blindagem.

Em resumo, a empresa trabalha com uma gama diversificada de produtos, a partir de várias formulações, que objetivam o atendimento das especificações fixadas pelos clientes. Os produtos são vendidos/armazenados em forma de rolos. Desse modo, um rolo pode ser intercalado ou refrigerado (de acordo com as condições de armazenagem previstas no destino), com a faixa degradee ou não, com diversas cores (vidros de arquitetura), com propriedades visuais (para indústria aeronáutica), com filtros, etc. Cada um destes atributos aumenta o valor agregado do produto.

Os clientes desta empresa realizam a laminação dos vidros a partir do produto acabado. Isto consiste em submeter o conjunto Vidro-PVB-Vidro a elevadas condições de pressão e de temperatura, conseguidas por meio de uma autoclave (equipamento que possui funcionamento similar a uma panela de pressão comum). No final, sobram as rebarbas deste processo, as quais são denominadas aparas, conforme esquematizado na Figura 4. As aparas não possuem valor agregado para o beneficiador

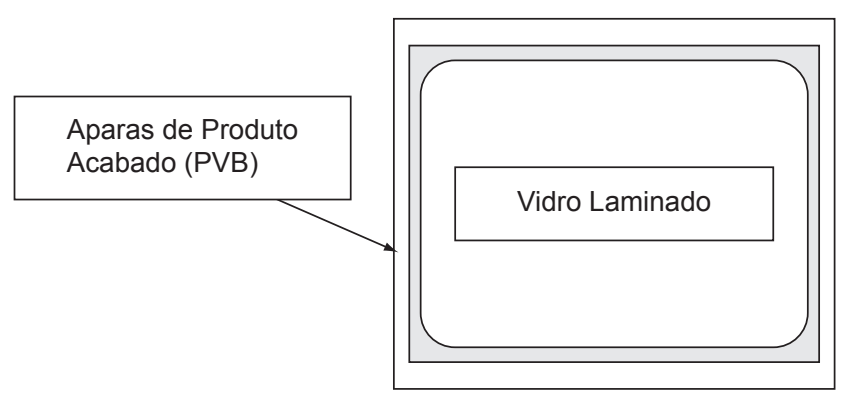

Figura 4. Formação das aparas.

do vidro laminado, mas podem ser reinseridas no processo de produção de PVB.

Até pouco tempo, essas aparas usualmente eram descartadas pelos beneficiadores de vidro, no entanto aspectos relativos ao impacto ecológico e financeiro ganharam relevância. A responsabilidade ecológica foi imposta via exigências de se cumprir normas internacionais como a ISO 14000. A questão financeira apareceu devido à vantagem competitiva que poderia ser obtida com a redução de custo na cadeia produtiva como um todo.

$\mathrm{Na}$ empresa em questão, foi estimado que, para os melhores beneficiadores, a área de aparas correspondia de 5 a $10 \%$ da área total utilizada na confecção do vidro laminado. Dessa maneira, para uma unidade do produto final, com área nominal de $250 \mathrm{~m}^{2}$, cujo preço de venda foi estimado em US $\$ 7,00 / \mathrm{m}^{2}$, havia uma perda com aparas entre US\$122,50 e US\$245,00 por unidade do produto final (ou seja, US\$ $0,49 / \mathrm{m}^{2}$ a US $\$ 0,98 / \mathrm{m}^{2}$ ).

Inicialmente, isso era motivo unicamente de preocupação do cliente. A partir do instante em que o descarte das aparas ficou sendo de responsabilidade da empresa em estudo, o cenário alterou-se e a empresa decidiu de- 
senvolver estudos para a adoção de práticas de Logística Reversa na reutilização das aparas geradas pelos seus clientes no processo produtivo.

Esses estudos mostraram que haveria a possibilidade de se oferecer descontos aos clientes que participassem do processo de Logística Reversa, variando de 1,5\% a $2,5 \%$ no preço de venda do material, já se excluindo, os custos de reprocesso e de transporte das aparas. Foi estimado também que as vantagens ainda poderiam ser maiores se fosse negociada uma política de fretes de retorno mais apropriada.

Na próxima seção, apresentam-se as principais fases para uma metodologia de implementação de LR, discutindo-se e ilustrando-se sua aplicação no problema das aparas de PVB.

\section{A transição para o processo de logísti- ca reversa de aparas}

Um passo importante para a implementação da Logística Reversa é o mapeamento e entendimento dos processos atuais. Nesse sentido, é de extrema utilidade o SCOR - Supply Chain Operations Reference -, que é um modelo de referência para o gerenciamento de Cadeias de Suprimentos de responsabilidade do Supply-Chain Council (www.supply-chain.org, acesso em 20/08/2004).

O modelo SCOR objetiva ajudar as empresas na avaliação do desempenho da sua própria cadeia, identificando áreas fracas e desenvolvendo soluções de melhoria. Nesse modelo, as atividades da empresa são divididas em cinco principais processos, como disposto na Figura 5, na qual está destacado o processo de retornos que é pertinente a este trabalho.

Para cada um dos processos descritos na Figura 5, o SCOR ajuda na escolha dos Indicadores Chave de Desempenho (Key Performance Indicators - KPI's) colaborando, assim, com as empresas na busca de um processo que adote as melhores práticas (benchmarking).

Aqui, procurou-se seguir as sugestões do modelo SCOR para o estudo de caso em questão, para verificar a aderência de tal metodologia à realidade de uma empresa nacional.

Após o mapeamento e entendimento dos principais (macros) processos da empresa, a próxima etapa é a definição das atividades do processo logístico reverso. Essa é uma etapa importante, visto que em muitas situações estas atividades se confundem ou se sobressaem sobre aquelas do processo logístico direto. Para ilustrar o procedimento citado, as atividades do fluxo reverso nesse estudo de caso envolveram:

- O planejamento do reuso de aparas (que é liberada de acordo com o planejamento de produção e do mix de produção de produtos acertados);
- A verificação do estoque de aparas (com relação à quantidade e ao tipo de aparas disponíveis, sendo este último importante para que se respeite o mix de produção, já que existem vários produtos e diferentes tipos de aparas associadas);

- A atualização do controle de estoque de aparas via um esquema Kanban;

- A solicitação do retorno - envolvendo o tipo e as quantidades de aparas;

- O agendamento do retorno - utilizando sistemas de fretes de retorno;

- O recebimento do produto;

- Reatualização do Kanban de estoque após o recebimento das aparas; $\mathrm{e}$

- A autorização da devolução ou crédito ao cliente que gerou o retorno.

Ainda, como exemplo, após uma análise realizada pelo setor de Planejamento e Controle da Produção (PCP) da empresa, observou-se que não era necessário manter um estoque elevado de todos os tipos de aparas disponíveis, o que ocuparia uma área razoável de armazenagem. Assim, foi devidamente acordado com os clientes, antes do processo de introdução do ciclo reverso, que haveria pequenos estoques tanto na empresa como nos clientes. Esta parceria ocorreu de forma que nenhum dos dois interessados viesse a ter estoques elevados de material de reuso, pois, especialmente em relação ao cliente, esse material não possui mais utilidade prática.

Definiu-se, assim, que o processo reverso implementado objetivaria proporcionar um retorno otimizado das aparas ao fornecedor. Observe-se que, antes dessa iniciativa, os clientes eram os responsáveis pela disposição final das aparas, ou seja, os custos eram somente deles e, além disso, não havia a possibilidade dos descontos na compra de novos produtos, isso foi introduzido após a adoção da Logística Reversa.

Na sequiência, passou-se à montagem de uma infraestrutura condizente com o porte do fluxo reverso que se pretendia reaproveitar. Para a empresa em questão, o fluxo reverso somente se justificaria caso existissem constância, controle e baixos estoques intermediários.

Assim, construiu-se uma estrutura próxima ao local de reprocessamento e um sistema paralelo ao do fluxo direto de produção na empresa. Para cada item vendido ou enviado para um warehouse intermediário, gera-se uma entrada vaga no sistema reverso. Ou seja, o sistema acusa na saída de um produto que existirá certo tipo de aparas disponível para um retorno futuro.

De acordo com a quantidade de produto enviada para o cliente, também se calcula a quantidade e data de retorno prevista de material de reuso. No entanto, estes da- 


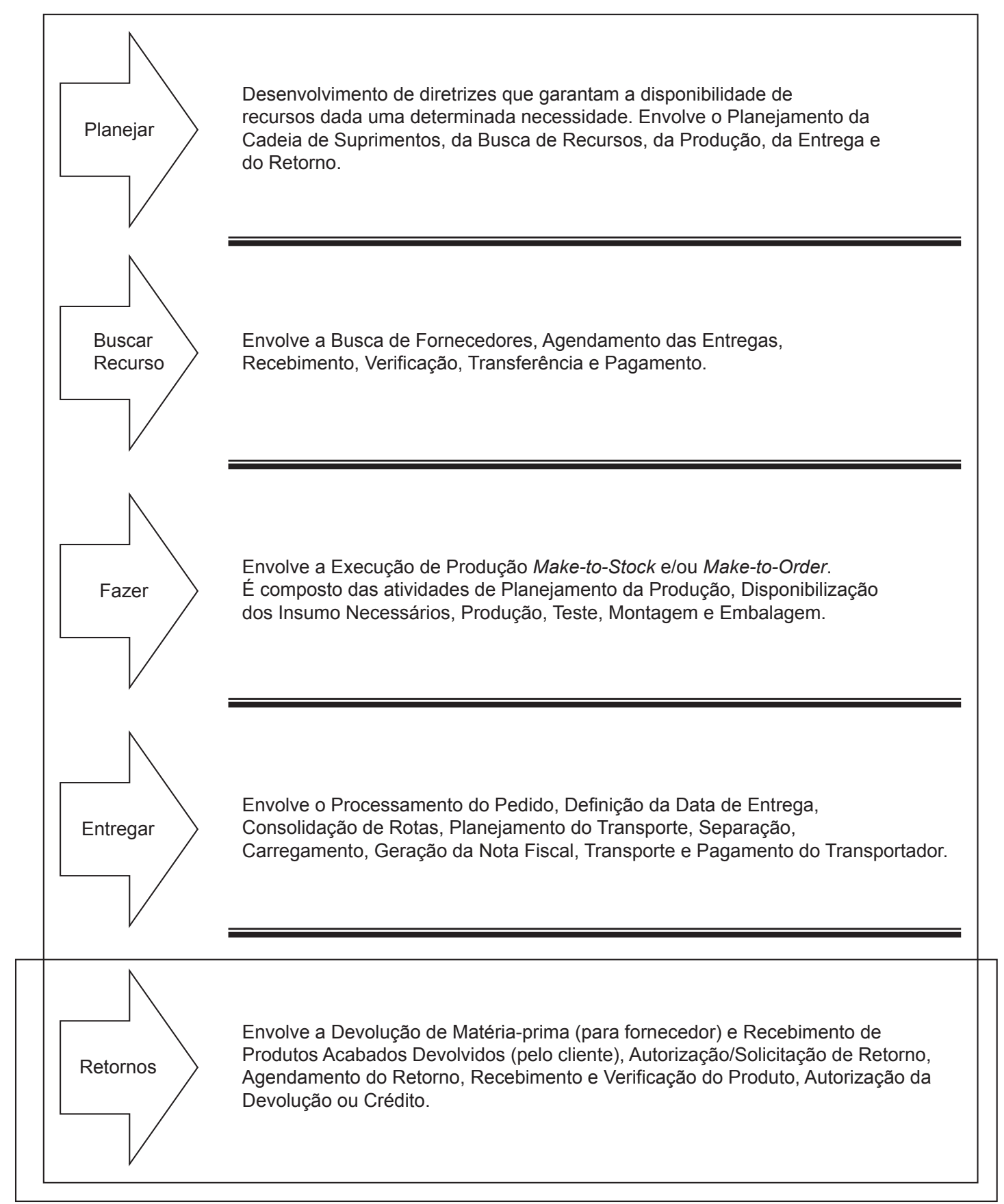

Figura 5. Atividades relacionadas à padronização dos processos - em destaque o processo de retorno (adaptado de www.supply.chain.org).

dos iniciais não servem para o planejamento da produção imediata, pois este é realizado com a quantidade de aparas realmente disponíveis para uso. Mas, para o planejamento logístico, essas informações são importantes, pois possibilitam o delineamento prévio da quantidade, tipo e época de retornos das aparas.

Destaque-se, ainda, que há uma margem de diferença nos volumes realmente obtidos no retorno com relação à quantidade em potencial de aparas que podem ser reutilizadas, pois o valor estimado de material de retorno pode sofrer alterações de acordo com os processos dos clien- tes. Isso é um fator importante, principalmente para não haver sub ou super estimação do volume de compra de matéria-prima para o mix de produtos destinados à produção pelo PCP.

Outro trabalho importante teve de ser desenvolvido junto aos setores de Planejamento e Controle da Produção e de Engenharia de Processos para viabilizar a introdução de novos mix de produção com o reuso das aparas. Foi necessária a introdução de um novo plano de reprocesso para as aparas, paralelo ao já existente para materiais reprovados pelo Controle de Qualidade, ainda 
no processo direto. Com a estabilização do fluxo reverso e a padronização dos métodos, esse tipo de atividade passou a ser usual.

Uma dificuldade adicional na implementação do processo de reuso de aparas ocorreu devido às alterações necessárias no sistema de planejamento e controle produtivo. A Logística Reversa foi uma variável adicional introduzida no planejamento hierárquico de produção, pois possibilitou a redução do consumo de matéria-prima virgem.

Deve ser evidenciado que, como o fluxo reverso se destinava ao reaproveitamento das aparas, ele só seria justificado caso existisse um correto planejamento da reutilização desse material em processo. Uma atividade de Logística Reversa realizada a esmo apenas encareceria os custos de produção.

Desse modo, a atividade reversa foi incluída no Macro-Planejamento, quando a gestão da demanda é realizada de forma agregada, e também no Micro-Planejamento, no qual a gestão da demanda é realizada em relação aos clientes potenciais.

Na seção 6, são apresentados os principais fatores que afetam a eficiência de uma implementação de Logística Reversa, exemplificando-se com o que ocorreu no estudo de caso.

\section{Fatores que influenciam a eficiência do processo de logística reversa}

O processo de Logística Reversa pode ter uma maior ou menor eficiência. Existem para isto alguns fatores críticos que condicionam o sistema (Rogers e Tibben-Lembke, 1999):

- Controles de Entrada (Gatekeeping);

- Mapeamento e Formalização do Processo;

- Tempo de Ciclo dos Produtos;

- Sistemas de Informação;

- Infra-estrutura Logística; e

- Relações entre Clientes e Fornecedores.

Em relação aos controles de entrada é necessário identificar corretamente o estado dos materiais que retornam para facilitar o fluxo logístico reverso (e para que possam ser bem reutilizados) e impedir que materiais estranhos integrem este fluxo logístico (gerando despesas e serviços desnecessários). Sistemas de Logística Reversa que possuem controles de entrada defasados geram sérias dificuldades posteriores.

Para a empresa laminadora de vidros, existiam alguns complicadores nesse sentido. Em indústrias químicas - como é a situação aqui relatada -, o mix de processo é muito importante, pois o processo é muito sensível às mudanças nas características dos insumos, ou seja, pe- quenas mudanças nos insumos afetam de forma drástica o produto, ocasionando necessidade de retrabalho.

Nesse aspecto, foi necessário envidar esforços para a correta identificação da proveniência do material que entraria em reprocesso. Isto foi conseguido por meio de um sistema de código de barras e lotes. Para cada lote de material revendido, associou-se um código específico de saída e uma lacuna para reentrada do material retornado. Isto facilitou em termos de set ups de processo e do controle de propriedades físicas e químicas do produto acabado. O Plano Mestre de Produção também foi alterado e passou a ter duas vertentes: o plano de processo regular e o plano de reprocesso de aparas.

Muitas empresas consideram o uso da Logística Reversa como um processo esporádico e não regular, isso provoca a ausência de processos mapeados e procedimentos formalizados. No estudo de caso em questão, esta visão míope atrapalhou muito o trabalho dos setores de Planejamento e Controle da Produção e de Engenharia de Processo no equacionamento de um sistema de Logística Reversa adequado, ou seja, que não gerasse inconvenientes ao processo.

Outro aspecto importante considerado foi o tempo de ciclo dos produtos, que inclui desde a identificação da necessidade de reutilização de aparas até o seu reprocessamento. Sabe-se que, se os tempos de ciclos forem muito longos, eles acabam por adicionar custos desnecessários porque atrasam a geração de caixa e ocupam espaço de armazenamento (Lacerda, 2002).

Stock (1998) relata que alguns fatores que aumentam o tempo de ciclo são: controles de entrada ineficiente, falta de infraestrutura dedicada ao fluxo reverso e falta de procedimentos para tratar as exceções ou resíduos de produtos de baixa saída ou elevado valor agregado. De fato, todos esses problemas ocorreram num projeto piloto realizado pela empresa laminadora de vidros envolvendo um cliente de grande porte, selecionado para testar o sistema de logística reversa em desenvolvimento. Naturalmente, eles foram solucionados antes da inclusão dos demais clientes no sistema.

A empresa laminadora de vidros percebeu a relevância de informações sobre a rastreabilidade dos retornos, medição do tempo de ciclo e a medição do desempenho de seus fornecedores de sucata. Com essas informações, obtidas por meio de um Sistema de Informação adequado, foi possível estabelecer Indicadores de Desempenho (KPI's) que foram fundamentais para a negociação, melhoria de desempenho e redução dos abusos dos fornecedores de sucata.

Infelizmente, praticamente são inexistentes no mercado sistemas capazes de lidar com o número de variações e flexibilidade necessárias a uma rede Logística Reversa. A Figura 6 apresenta as tecnologias instaladas nas em- 
Tecnologias Instaladas

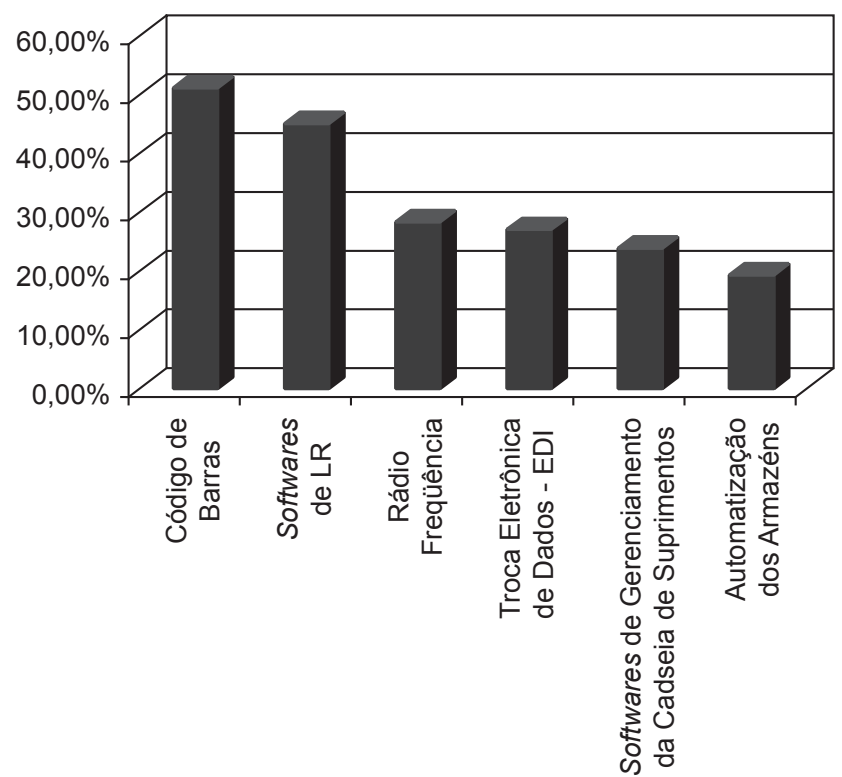

Figura 6. Tecnologias instaladas nas empresas que adotam sistemas de Logística Reversa. (Adaptado de Rogers e Tibben-Lembke, 1999).

presas consultadas por Rogers e Tibben-Lembke (1999) que adotam sistema de Logística Reversa.

No estudo de caso, incorporou-se ao sistema, já existente, de controle de estoque um sistema paralelo de controle do fluxo reverso, sendo ambos corporativos. Uma outra idéia implementada foi a introdução de um sistema Kanban que manteve o fluxo de aparas constante ao longo do tempo e minimizou os estoques necessários para o reprocesso.

A implementação de um processo logístico reverso requer uma infra-estrutura logística adequada (Fleischmann, 2001b) para lidar com os fluxos de entrada dos materiais reutilizados. Instalações de armazenagem e sistemas de controle devem ser desenvolvidos para interligar de forma eficiente os pontos de coleta (clientes) até o ponto de consumo (empresa).

Questões relativas à escala de movimentação e à falta do correto planejamento logístico podem levar ao uso das mesmas instalações no fluxo direto e reverso. Isso pode acabar sacrificando a eficiência de um dos ciclos ou congestionando a rede logística. No estudo de caso, a solução adotada foi criar um depósito de aparas junto à área de reprocesso, com isso economizou-se em tempo de transporte, reduziram-se os lead-times e desvinculouse a armazenagem das aparas dos armazéns de produto acabado.

Por fim, deve ocorrer um bom nível de confiança no relacionamento cliente-fornecedor, notadamente com respeito às atividades de responsabilidades de ambos num processo de Logística Reversa. No estudo de caso, as aparas eram adquiridas a custo zero dos clientes, que viam nisto apenas uma forma de dar fim ao resíduo do seu processo. A introdução de um sistema de controle e planejamento nesse ambiente, inicialmente, não foi bem aceita pelos clientes, pois exigiria um trabalho adicional por parte deles.

Para convencer os fornecedores de sucata a aceitarem as novas políticas de planejamento logístico, foram firmadas parcerias do tipo ganha-ganha (win-win relationship), da seguinte forma:

- Para os clientes com ganhos de escala, ou seja, compradores de grandes quantidades de produto, foram propostos descontos variando entre $1,5 \%$ e $2,0 \%$ no valor de compra do produto acabado, como forma de incentivo à prática de políticas de redirecionamento de material. Isso também serviu como uma credencial para a regulamentação na ISO 14000; e

- Para os clientes de pequeno porte, os descontos de pequenas taxas percentuais refletiam pouco o retrabalho necessário para redirecionamento de material. Dessa forma, foram oferecidas, e satisfizeram as necessidades dessa classe de clientes, outras práticas como: facilidades de pagamento, sistemas de entrega do tipo porta a porta (door-to-door) e melhor atendimento no pós-vendas.

Com essas políticas, procurou-se evitar que, em situações extremas, conflitos entre fornecedor e cliente pudessem gerar recusa no aceite de devoluções e atrasos, que requereriam a adoção de dispendiosas medidas de controle. Isto dificultaria em muito o trabalho das equipes de planejamento e processo no equacionamento do set up de produção conveniente, conforme já foi comentado por Fleischmann et al. (2001).

\section{Comentários finais}

A Logística Reversa ainda é uma área de baixa prioridade dentro da Cadeia de Suprimentos das empresas nacionais (Lacerda, 2002). Embora ainda se esteja em um estado inicial de desenvolvimento de políticas de Logística Reversa, pressões externas de legislação ambiental e a procura de novos modos para redução de custo têm exigido a evolução das empresas nesse quesito.

Os novos paradigmas para o setor industrial em todo o mundo deverão ser: ser responsável pelos seus produtos e embalagens, desde o projeto até a sua disposição final (Product Stewardship); e, nos projetos de produtos e embalagens, considerar não só a viabilidade da manufatura, mas também facilitar a desmontagem, a sua manutenção e eventual reciclagem, além do uso eficiente de recursos naturais (to design for manufacture, and disassembly, and for maintainability, and energy efficiency, and recycling).

A tendência é que, com o aumento do fluxo reverso de carga, o custo deste processo também aumente. As empresas mais bem adaptadas a este processo buscarão me- 
lhores desempenhos na cadeia e isto se refletirá em maior flexibilidade, velocidade e qualidade na cadeia logística.

Para que isso ocorra as mesmas técnicas de Pesquisa Operacional aplicadas ao fluxo direto deverão ser reelaboradas para o fluxo reverso (Dekker et al., 1998), tais como, planejamento da rede logística, métodos de estudo de localizações, estudo de transportes, entre outras possibilidades (Ballou, 2006).

Nesse estudo de caso, pôde-se constatar que a implementação de um processo de Logística Reversa além de conduzir à satisfação de exigências normativas, como a ISO 14000 , pode levar a uma redução de custo no produto acabado, principalmente quando existe o reuso do material de descarte.

Outro aspecto foi a constatação da vantagem de se adotar o que é preconizado pelo modelo de referência $S C O R$, o qual demonstrou ser perfeitamente aplicável à cadeia de suprimentos da laminação de vidros.

Uma grande vantagem encontrada na empresa estudada, após a implementação do sistema reverso, foi o ganho de know-how sobre o sistema logístico completo. A empresa passou a conhecer melhor as demais atividades na cadeia de suprimentos e pôde otimizá-las. Esse resultado foi coerente com o que aponta o Supply-Chain Council (2003), responsável pelo modelo SCOR, no sentido de que, freqüentemente, a implementação do sistema reverso conduz a melhores Indicadores Chave de Desempenho do fluxo direto, incluindo novas economias que ainda não eram consideradas. Esse é um fator de redução de custo importante, mas pouco considerado na implementação do sistema reverso.

Surgiram, também, economias devido à escala de produção na quantidade de compra de matérias-primas, bem como economias nos fatores de processo (energia, mãode-obra, manutenção, etc.), já que o fluxo do material de reuso no processo produtivo é menor, visto que ele já é um material semipronto.

Outro fator interessante refere-se à economia financeira obtida para todos os outros parceiros da Cadeia. Só para exemplificar, o volume de um dos principais materiais nessa manufatura era da ordem de $200.000 \mathrm{~m}^{2}$. Supondo ser $5 \%$ a área de aparas, tem-se uma quantidade de $10.000 \mathrm{~m}^{2}$ de material de reuso, o que resulta em um decréscimo de US\$ 70.000 com relação ao preço de venda (vantagem para o cliente) e de uma economia de US\$ 30.000 com relação aos custos de produção (vantagem para o produtor). Assim, criou-se a possibilidade de produtor e clientes negociarem melhores preços e fazer com que seus produtos se tornassem mais baratos e competitivos.

Além disso, o fluxo reverso melhorou a rotatividade do inventário de matéria-prima e reduziu os estoques. Esses custos importantes ainda não foram computados pela empresa laminadora de vidros.
A inexistência de sistemas de informação voltados para a Logística Reversa, assim como o elevado número de situações que são exceções às regras, exige um grande esforço para o estabelecimento de políticas de Logística Reversa (Lacerda, 2002). No estudo de caso, optou-se pelo desenvolvimento de sistemas corporativos para o controle do estoque e do fluxo de sucata.

Nesse sentido, o que deve ser explorado pelas empresas é a utilização de Prestadores de Serviços Logísticos (Third-Party Logistics Providers - 3 PLPs) no processo de Logística Reversa, visto que essa atividade exige o fator da economia de escala e os fluxos reversos ainda são pequenos (Rogers e Tibben-Lembke, 1999). Isso já ocorre em empresas como a Embraer e a Du Pont, e já é comum para o gerenciamento do fluxo de retorno de paletes, podendo ser citado o caso da CHEP (www.chep. com.br - acesso em 09/03/2004) que oferece um serviço de gerenciamento de paletes e contentores de vários tipos para toda a cadeia de suprimentos.

Finalmente, podem ser sugeridos alguns desdobramentos futuros deste artigo:

- Verificar o impacto da Logística Reversa na redução dos custos totais da cadeia;

- Analisar a viabilidade técnica e financeira de utilizar prestadores de serviço logístico nas atividades da Logística Reversa;

- Melhorar a colaboração na cadeia de suprimentos;

- Implementar uma Análise de Ciclo de Vida para a cadeia reversa (Daniel e Pappis, 1999); e

- Desenvolver Sistemas de Informação especializados para as atividades da Logística Reversa que possam ser integrados aos sistemas de informação existentes no mercado para o gerenciamento total da cadeia.

Finalmente, é importante destacar, como contribuição deste artigo, a descrição completa de um estudo de caso envolvendo o sério problema que é a disposição final de vidro (cuja decomposição demora cerca de 150 anos), mostrando o uso de uma metodologia de implementação de sistemas de logística reversa bem sucedida, como as dificuldades que surgiram foram resolvidas pela adoção dos conceitos de Logística Reversa, aliados ao bom senso da equipe de trabalho da empresa laminadora de vidros, além de uma discussão acerca de como os parceiros envolvidos podem ganhar, tanto do ponto de vista econômico como em conhecimento (know how).

\section{Agradecimentos}

À FUNDUNESP - Fundação para o Desenvolvimento da UNESP, Universidade Estadual Paulista - pelo suporte financeiro e aos referees anônimos que contribuíram com várias sugestões relevantes. 
BALLOU, R. H. Gerenciamento da Cadeia de Suprimentos/Logística Empresarial - 5a. edição. Porto Alegre: Bookman Editora, 2006. 616 p.

BERTO, R. M. V. S.; NAKANO, D. N. Métodos de Pesquisa na Engenharia de Produção. In: ENCONTRO NACIONAL DE ENGENHARIA DE PRODUÇÃO, 18, 1998, Niterói. Anais... Niterói: UFF/ABEPRO, 1998. CD-ROM.

BOWERSOX, D. J.; CLOSS, D. J. Logística Empresarial - o processo de integração da cadeia de suprimento. São Paulo: Editora Atlas, 2001. 594 p.

CERVO, A. C.; BERVIAN, P. A. Metodologia Científica. 4a . ed. São Paulo: Makron Books, 1996. 203 p.

CHOPRA, S.; MEINDL, P. Gerenciamento da Cadeia de Suprimentos. São Paulo: Prentice Hall, 2003. 465 p.

CARTER, C. R.; ELLRAM, L. M. Reverse Logistics: A review of the literature and framework for future investigation. Journal of Business Logistics, v. 19, issue 1, p. 85-102, 1998.

CARUSO, C.; COLORNI, A.; PARUCCINI, M. The regional urban solid waste management system: a modelling approach. European Journal of Operational Research, v. 70, issue 1, Oct, p. 16-30, 1993.

DANIEL, S.; PAPPIS, C. Applying life cycle impact assesment to reverse supply chains: a case study. Working paper DPV/12/99, University of Piraeus, Greece, 1999.

DEKKER, R.; BLOEMHOF-RUWAARD, J.; FLEISCHMANN, M.; VAN DER LAAN, E. A.; VAN NUNEN, J.; VAN WASSENHOVE, L. N. Operational Research in reversed logistics: some recent contributions. International Journal of Logistics: Research and Applications, v. 1, n. 2, p. 141-155, 1998.

DEKKER, R.; FLEISCHMANN, M.; INDERFURTH, K.; van WASSENHOVE, L. N. Reverse Logistics: Quantitative Models for Closed-Loop Supply Chains. New York: Springer-Verlag, 2004. 390 p.

DEL CASTILLO, E.; COCHRAN, J. K. Optimal short horizon distribution operations in reusable container systems. Journal of The Operational Research Society, v. 47, n. 1, p. 8-60, 1996.

DOBOS, I. Optimal production-inventory strategies for an HMMS-type reverse logistics system. International Journal of Production Economics, v. 81-82, p. 351-360, 2003.

DOWLATSHAHI, S. Developing a theory of reverse logistics. Interfaces, v. 30, n. 3, May-June, p. 143-155, 2000.
FERRER, G.; KETZENBERG, M. E. Value of information in remanufacturing complex products. IIE Transactions, v. 36, issue 3, Mar, p. 265-277, 2004.

FLAPPER, S. D. P.; TEUNTER, R. H. Logistic planning of rework with deteriorating work-in-process. International Journal of Production Economics, v. 88, p. 51-59, 2004.

FLEISCHMANN, M.; BLOEMHOF-RUWAARD, J. M.; DEKKER, R.; VAN DER LAAN, E.; VAN NUNEN, J. E. E.; VAN WASSENHOVE, L. N. Quantitative Models for Reverse Logistics: a review. European Journal of Operational Research, v. 103, issue 1, p. 1-17, 1997.

FLEISCHMANN, M.; BEULLENS, P.; BLOEMHOFRUWAARD, J. M.; VAN WASSENHOVE, L. N. The impact of product recovery on logistics network design. Production and Operations Management, v. 10, n. 2, Summer, p. 156-173, 2001.

FLEISCHMANN, M., Quantitative Models for Reverse Logistics. Berlin: Springer-Verlag, 2001a. 181 p.

Reverse Logistics Network Structures and Design. ERIM Report Series Research in Management, ERS2001-52-LIS, Erasmus Research Institute of Management, Rotterdam, the Netherlands, 2001b. 21 p.

FLEISCHMANN, M., VAN NUNEN, J. A. E. E.; GRAVE, B. Integrating Closed-Loop Supply Chains and SpareParts Management at IBM. Interfaces, v. 33, issue 6, Nov/Dec, p. 44-56, 2003.

GIUNTINI, R.; ANDEL, T. Reverse Logistics Role Models: Part 3. Transportation and Distribution, v. 36, n. 4, p. 97-98, 1995.

GIUNTINI, R.; GAUDETTE, K. The next great opportunity for boosting US productivity. Business Horizons, v. 46, issue 6, Nov/Dec, p. 41-48, 2003.

GONZÁLEZ-TORRE, P. L.; ADENSO-DÍAZ, B.; ARTIBA, $\mathrm{H}$. Environmental and reverse logistics policies in European bottling and packing firms. International Journal of Production Economics, v. 88, n. 1, p. 95-104, 2004.

GUIDE JR, V. D.; VAN WASSENHOVE, L. N. Managing product returns for remanufacturing. Production and Operations Management, v. 10, issue 2, Summer, p. 142-155, 2001.

GUIDE JR, V. D.; JAYARAMAN, V.; LINTON, J. D. Building contingency planning for closed-loop supply chains with product recovery. Journal of Operations Management, v. 21, issue 3, May, p. 259-279, 2003.

HEESE, H. S.; CATTANI, K.; FERRER, G.; GILLAND, W.; ROTH, A. V. Competitive advantage through take- 
back of used products. European Journal of Operational Research, v. 164, issue 1, Jul, p. 143-157, 2005.

KIESMÜLLER, G. P.; SCHERER, C. W. Computational issues in a stochastic finite horizon one product recovery inventory model. European Journal of Operational Research, v. 146, n. 3, p. 553-579, 2003.

KRIKKE, H. R.; KOKKINAKI, A. I.; VAN NUNEN, J. A. E. E. Network Design in Reverse Logistics: A Quantitative Model, editors M. G. Speranza e P. Staehly, Lectures Notes in Economics and Mathematical Systems. Berlin: Springer Verlag, Chapter 1, p. 45-62, 1999. 480 p.

KROON, L.; VRIJENS, G. Returnable containers: an example of reverse logistics. International Journal of Physical Distribution e Logistics Management, v. 25, n. 2, p. 56-68, 1995.

LACERDA, L. Logística Reversa - Uma visão sobre os conceitos básicos e as práticas operacionais. Centro de Estudos em Logística - COPPEAD, 2002. Disponível em <www.cel.coppead.ufrj.br $>$. Acesso em 20 de agosto de 2004.

LAI, K. K.; KOKIN, L.; CHAN, W. K. Shipping container logistics and allocation. The Journal of the Operational Research Society, v. 46, issue 6, p. 687-697, 1995.

LAKATOS, E. M.; MARCONI, M. A. Fundamentos de Metodologia Científica. $3^{\circ}$. ed. São Paulo: Editora Atlas, 1991. $270 \mathrm{p}$.

LEITE, P. R. Logística Reversa - Meio Ambiente e Competitividade. São Paulo: Prentice Hall, 2003. 250 p.

LINTON, J. D.; YEOMANS, J. S.; YOOGALINGAM, R. Supply planning for industrial ecology and remanufacturing under uncertainly: a numerical study of leadedwaste recovery from television disposal. The Journal of the Operational Research Society, v. 53, issue 11, Nov, p. 1185-1196, 2002.

LUMMUS, R. R.; VOKURKA, R. J. Defining supply chain management: a historical perspective and practical guidelines. Industrial Management e Data Systems, v. 99, n. 1, p. 11-17, 1999.

LUND, R. T. Remanufacturing. Technology Review, v. 87, issue 2, Feb/Mar, p. 18-23, 1984.

MINNER, S. Multiple-supplier inventory models in supply chain management: A review. International Journal of Production Economics, v. 81-82, p. 265-279, 2003.

MORITZ, F.; BEULLENS, P.; BLOEMHOF-RUWAARD, J. M.; van WASSENHOVE, L. The impact of product recovery on logistics network design. Production and Operations Management, v. 10, n. 2, p.156-173, 2001.

NOVAES, A. G. Logística e Gerenciamento da Cadeia de Suprimentos. Rio de Janeiro: Editora Campus, 2001. 409 p.
ROGERS, D. S., TIBBEN-LEMBKE, R. S. Going Backwards: Reverse Logistics Trends and Practice. Reverse Logistics Executive Council, 1999. Disponível em <http://www.rlec.org/reverse.pdf>. Acesso em $20 \mathrm{de}$ agosto de 2004.

STOCK, J. R. Development and Implementation of Reverse Logistics Programs. Council of Logistics Management, 1998. 247 p.

TEUNTER, R. H.; VAN DER LAAN, E.; INDERFURTH, $\mathrm{K}$. How to set the holding cost rates in average cost inventory models with reverse logistics? Omega, v. 28, n. 4, p. 409-415, 2000.

TEUNTER, R. H.; FLAPPER, S. D. P. Lot-sizing for a single-stage single-product production system with rework of perishable production defectives. OR Spectrum, v. 25, n. 1, p. 85-96, 2003.

TOFFEL, M. W. Closing the Loop: Product Take-Back Regulations and Their Strategic Implications. International Journal of Corporate Sustainability, v. 10, issue 9, October, p. 161-172, 2003.

VAN DER LAAN, E.; DEKKER, R.; SALOMON, M. Product remanufacturing and disposal: a numerical comparison of alternative control strategies. International Journal of Production Economics, v. 45, issue 1-3, Aug, p. 489-498, 1996.

VAN NUNEN, J. A. E. E.; ZUIDWIJK, R. A. E-Enable Closed-Loop Supply Chains. California Management Review, v. 46, issue 2, Winter, p. 40-54, 2004.

$<$ http:www.supply-chain.org> sítio do Supply-Chain Operations Reference-Model-Overview Version 5.0. Acesso em 20 de agosto de 2004.

<http:www.cscmp.org> sítio do Council of Supply Chain Management Professionals. Acesso em 10 de outubro de 2004.

<http://www.pro-e.org/05europe/text/94_62_EC.pdf> sítio do Euro-lex. Acesso em 14 de fevereiro de 2005.

<http://europa.eu.int/eur-lex/pri/en/oj/dat/2004/1_047/1_ 04720040218en00260031.pdf> Acesso em 14 de fevereiro de 2005 .

$<$ http://www.ecocycle.org/zero/takeback.cfm> sítio do Ecocycle. Acesso em 14 de fevereiro de 2005.

<http://www.abal.org.br> sítio da Associação Brasileira de Alumínio. Acesso em 19 de fevereiro de 2005.

<http://www.abipet.org.br> sítio da Associação Brasileira das Indústrias PET. Acesso em 19 de fevereiro de 2005.

<http://www.reciclagem.pcc.usp.br> sítio do Reciclar para Construir. Acesso em 19 de fevereiro de 2005.

<http://www.cempre.org.br> sítio do Comitê Brasileiro de Reciclagem. Acesso em 19 de fevereiro de 2005. 
<http://www.latasa.com.br> sítio da Rexam Beverage Can South América. Acesso em 19 de fevereiro de 2005.

$<$ http://www.fbk.eur.nl/OZ/REVLOG> sítio do European Working Group on Reverse Logistics. Acesso em 21 de agosto de 2004.
$<$ http://www.gdrc.org/uem/lca/life-cycle.html> sítio da Life Cycle Analysis and Assessment. Acesso em 10 de março de 2005.

$<$ http:www.rlec.org> sítio do Reverse Logistics Executive Council. Acesso em 21 de agosto de 2004.

$<$ http:www.chep.com.br> sítio da CHEP- Equipment Pooling Systems. Acesso em 09 de março de 2004.

\title{
REVERSE LOGISTICS IN A GLASS LAMINATION INDUSTRY: A CASE STUDY
}

\begin{abstract}
This paper introduces a Reverse Logistics application in a multinational plastic film industry in Brazil, where the waste generated by its customers can reload the production process. Firstly, the main features concerning the theme and the factors that influence an efficient process of Reverse Logistics are discussed. Afterwards, using a case study, the steps focusing on the implementation of Reverse Logistics, which were successful in a company, are introduced and discussed. Finally, the difficulties, gains and competitive advantages obtained by the companies that have adopted Reverse Logistic solutions, particularly the company where the case study was developed, are commented upon.
\end{abstract}

Keywords: supply chain management, Reverse Logistics, case study, glass lamination. 